\title{
Comparison of Efficacy of Different Afforestation Techniques with Seed Wombs
}

\author{
Nagaveni Aspalli $^{1^{*}}$, Uday Kumar Nidoni ${ }^{2}$, K.J.Hemalatha ${ }^{3}$ and Shivanand Aspalli ${ }^{4}$ \\ ${ }^{1}$ Aspalli Green Sustainable Ecosystem Pvt Ltd, Prof Conservative Dentistry and Endodontics \\ HKDTE's Dental College, Humnabad, India \\ ${ }^{2}$ Department of Processing \& Food Engineering \& Research Engineer, AICRP on PHET, \\ College of Agricultural Engineering, Raichur-584102(Karnataka) \\ ${ }^{3}$ Department of Horticulture, University of Agricultural Sciences, ICAR,KVK, \\ Raichur, India \\ ${ }^{4}$ Aspalli Green Sustainable Ecosystem Pvt Ltd, Department of Periodontics and Implantology \\ A.M.E's Dental College, Hospital and Research Centre, Raichur \\ *Corresponding author
}

\section{Ke y words}

Seed Wombs, Different Afforestation Techniques

\section{Article Info}

Accepted: xx January 2019 Available Online: xx February 2020
Global warming is currently at the century peak with high temperature rise, draught, expanding deserts, scanty rainfall, drying up of lakes, ponds, rivers and underground water levels. Various species of insects, birds and animals are now either extinct or endangered. Greenhouse gases such as carbon dioxide, methane and nitrous oxide are at alarming high rates causing threat to life on earth. Reforestation of earth is the only solution. We are only dependent on saplings to grow trees globally. Though there are lakhs of products in the market, there is no single ready to use product to grow trees. In this regard, Dr.Nagaveni Aspalli from Raichur Karnataka, India has developed a product called 'Seed womb'. Seed wombs are ultraportable, scientific effective patent pending products to grow all varieties of plant species. They do not require daily watering, no digging pits required, does not get damaged by wind, heat and pests. They can be spread all round the year. Once rain water falls on it, germinataion and growth of seeds begins. This study is done to evaluate the rate of germination and growth of seeds in seed wombs, saplings, seed balls and plain seeds and to find out the best method to grow trees for afforestation and to demonstrate the potential solution for global warming and climate change. 


\section{Introduction}

The speed and extent of current global warming exceeds any similar event in the past 2,000 years, researchers say ${ }^{8}$. Rising temperature all over the world with climate change has resulted in global warming. It may cause severe changes in quality of air, water and soil. High temperature is now being recognized as a potential agricultural threat for the world ${ }^{5}$. Diseases such as asthma, cancer, birth defects and various other diseases have become epidemic. Farmers are severely affected by drought as it is more difficult to grow crops with low soil moisture and no water availability and reduction in soil nutrient levels ${ }^{2}$.

The solution for all these problems is immediate reforestation of the planet. Though, lakhs of products are available in the market, there is no single ready to use product in the market to grow plants and trees. Dr.Nagaveni Aspalli after extensive research, developed seed wombs. Seed wombs are like mothers womb. They protect the seeds from heat, wind and pests. Keeps the seeds alive and help them germinate when water is available. They provide all the nutrients required for seeds to germinate and help them and protect them until they are big enough to self sustain. They have water reservoir and moisture retaining components. They do not require regular watering. Seed wombs of all varieties of plants and trees can be made. They do not require digging pits. Are very light weight. Are easy to carry while travelling, trecking etc. They can be spread using aircrafts too to create forests in inaccessible and large areas. They have a shelf life of 6 months to one year. Are very economical. Seed womb must be placed where it is wished to be grown. That makes it practically easiest and most effective method to grow trees. The design of seed womb is such that it rests on the base itself when thrown. Since it is practically easy, active people participation can be achieved. Seed wombs are 100 percent effective. Forests can be regenerated, water bodies rejuvinated, pollution reduced, temperature reduced, creates clean green healthy ecosystem and biodiversity.

\section{Materials and Methods}

The experiment to evaluate the survival and rate of growth of seeds were carried twice, once using ladies finger seeds and second time using tamarind seeds.

Using Ladies finger seeds: In this study ladies finger seeds were placed in ten samples of each of a.seed wombs, b.saplings, c.seed balls and d.plain seeds of ladies finger. They were all planted/dispersed on the same day in Raichur, Karnataka . Seed wombs were placed on the soil. Saplings were grown for 1month and then planted after digging the soil. Seed balls were just thrown on the soil and seeds were dispersed manually on the soil. All the four groups had seeds from same packet of seeds. All the four groups were watered equally on day one by 1 litre of water. All of the samples of four different groups were exposed to same conditions (sunlight, temperature and humidity). All the parameters were standardised. They were not watered for 20 days. All the samples were evaluated on 20th day.

Using tamarind seeds: The same procedure using ladies finger seeds were followed and were evaluated on 20 th day.

Plant monitoring was done to document survival and growth rate like height, diameter of stem(the stem diameter being noted at a distance of $1 \mathrm{~cm}$ from base), number of leaves, root length. All treatment areas were monitored by walking the site and visually inspecting and noting the records. 


\section{Results and Discussion}

In both the experiments using ladies finger seeds and tamarind seeds, there was no germination of seeds in seed balls and in plain seeds. Hence, they were not considered for further evaluation as the survival rate was nil. The seeds had grown effectively in seed wombs group in all the 10 samples with respect to germination, height, stem diameter, number of leaves and root length.
There were statistically significant differences in the growth of first group (seed wombs) with all the three different groups(saplings, seed balls and seeds). Seed wombs had also shown robust germination and growth of the seedlings in both experiments using ladies finger seeds and using tamarind seeds. Seed wombs were statistically significantly superior in all parameters in both experimental groups compared to saplings, seed balls and plain seeds.

Table.1 Comparison between Seed Wombs and saplings of Ladies Finger seeds using MannWhiteny test

\begin{tabular}{|c|c|c|c|c|c|c|c|c|}
\hline & & Minimum & Maximum & Mean & S.D & Median & Mean diff & $\mathrm{P}$ value \\
\hline \multirow[t]{2}{*}{ Survival } & Seed wombs & 1 & 1 & 1.00 & .000 & 1.00 & \multirow{2}{*}{0.30} & \multirow{2}{*}{0.067} \\
\hline & Saplings & 0 & 1 & .70 & .483 & 1.00 & & \\
\hline \multirow[t]{2}{*}{ Height } & Seed wombs & 25 & 33 & 28.90 & 3.071 & 29.0 & \multirow[t]{2}{*}{26.70} & \multirow[t]{2}{*}{$0.00^{*}$} \\
\hline & Saplings & 0 & 8 & 2.20 & 3.553 & 0.00 & & \\
\hline \multirow[t]{2}{*}{ Stem diameter } & Seed wombs & 4 & 6 & 4.80 & .789 & 5.00 & \multirow[t]{2}{*}{4.10} & \multirow[t]{2}{*}{$0.00^{*}$} \\
\hline & Saplings & 0 & 3 & .70 & 1.160 & 0.00 & & \\
\hline \multirow{2}{*}{$\begin{array}{c}\text { Number of } \\
\text { leaves }\end{array}$} & Seed wombs & 13 & 20 & 16.40 & 2.221 & 16.50 & \multirow[t]{2}{*}{15.40} & \multirow[t]{2}{*}{$0.00^{*}$} \\
\hline & Saplings & 0 & 4 & 1.00 & 1.633 & 0.00 & & \\
\hline \multirow[t]{2}{*}{ Root length } & Score B & 11 & 14 & 12.30 & .949 & 12.00 & \multirow[t]{2}{*}{10.60} & \multirow[t]{2}{*}{$0.00^{*}$} \\
\hline & Score C & 0 & 6 & 1.70 & 2.751 & 0.00 & & \\
\hline
\end{tabular}

Table.2 Comparison between Seed Wombs and Saplings of Tamarind seeds using MannWhiteny test

\begin{tabular}{|c|c|c|c|c|c|c|c|c|}
\hline & Minimum & Maximum & Mean & S.D & Median & Mean diff & P value \\
\hline Survival & Seed wombs & 1 & 1 & 1.00 & .000 & 1.00 & 0.50 & $0.012^{*}$ \\
\cline { 2 - 10 } & Saplings & 0 & 1 & .50 & .527 & 0.50 & & \\
\hline Height & Seed wombs & 11 & 15 & 12.50 & 1.354 & 12.50 & 9.70 & $0.00^{*}$ \\
& Saplings & 0 & 6 & 2.80 & 2.974 & 2.50 & & \\
\hline $\begin{array}{c}\text { Stem } \\
\text { diameter }\end{array}$ & Seed wombs & 4 & 6 & 5.20 & .789 & 5.00 & 3.90 & $0.00^{*}$ \\
\hline $\begin{array}{c}\text { Number } \\
\text { of leaves }\end{array}$ & Saplings & 0 & 3 & 1.30 & 1.418 & 1.00 & & \\
\hline $\begin{array}{c}\text { Root } \\
\text { length }\end{array}$ & Sed wombs & 2 & 4 & 3.10 & .568 & 3.00 & 2.60 & $0.00^{*}$ \\
\hline
\end{tabular}




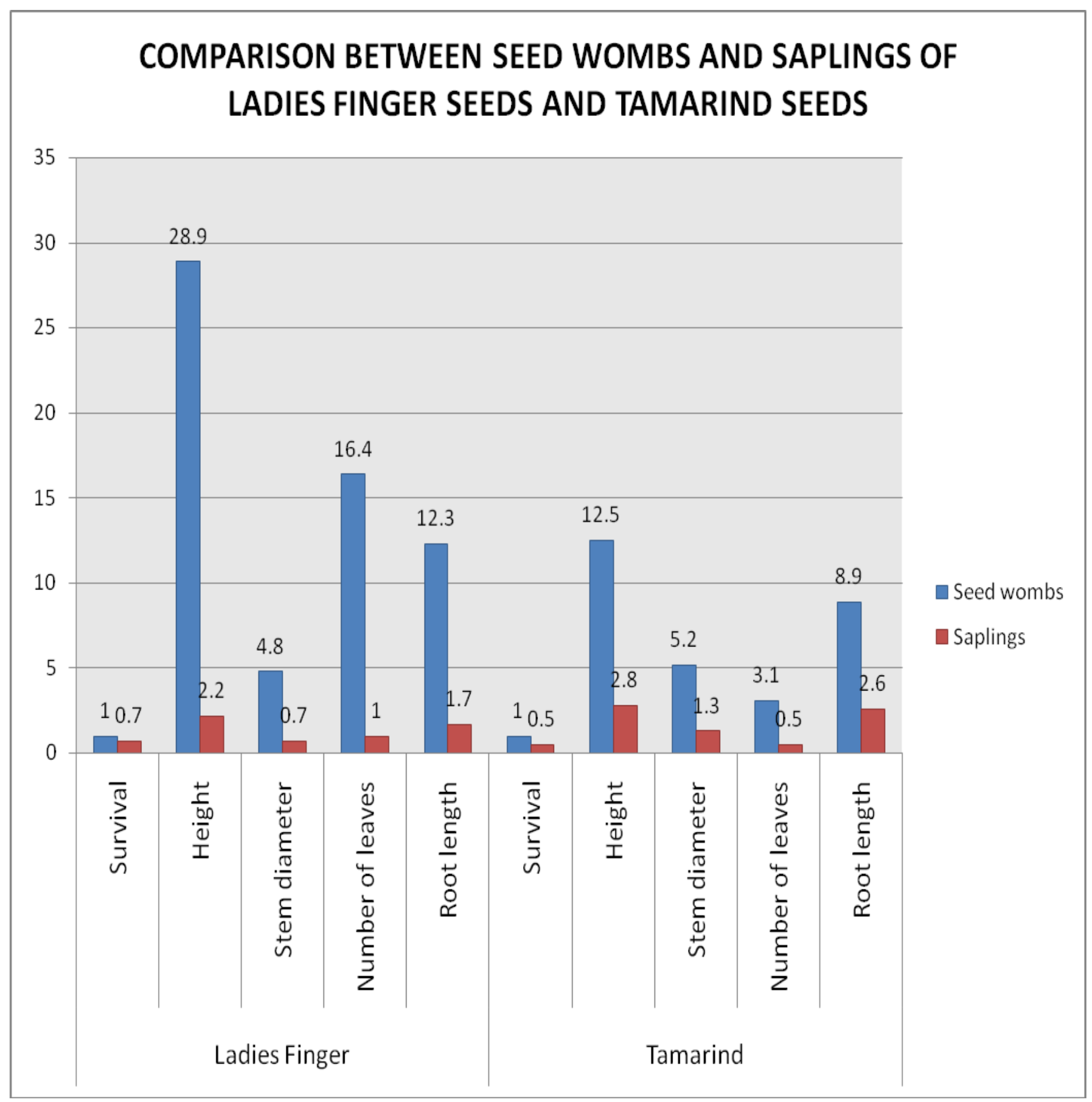




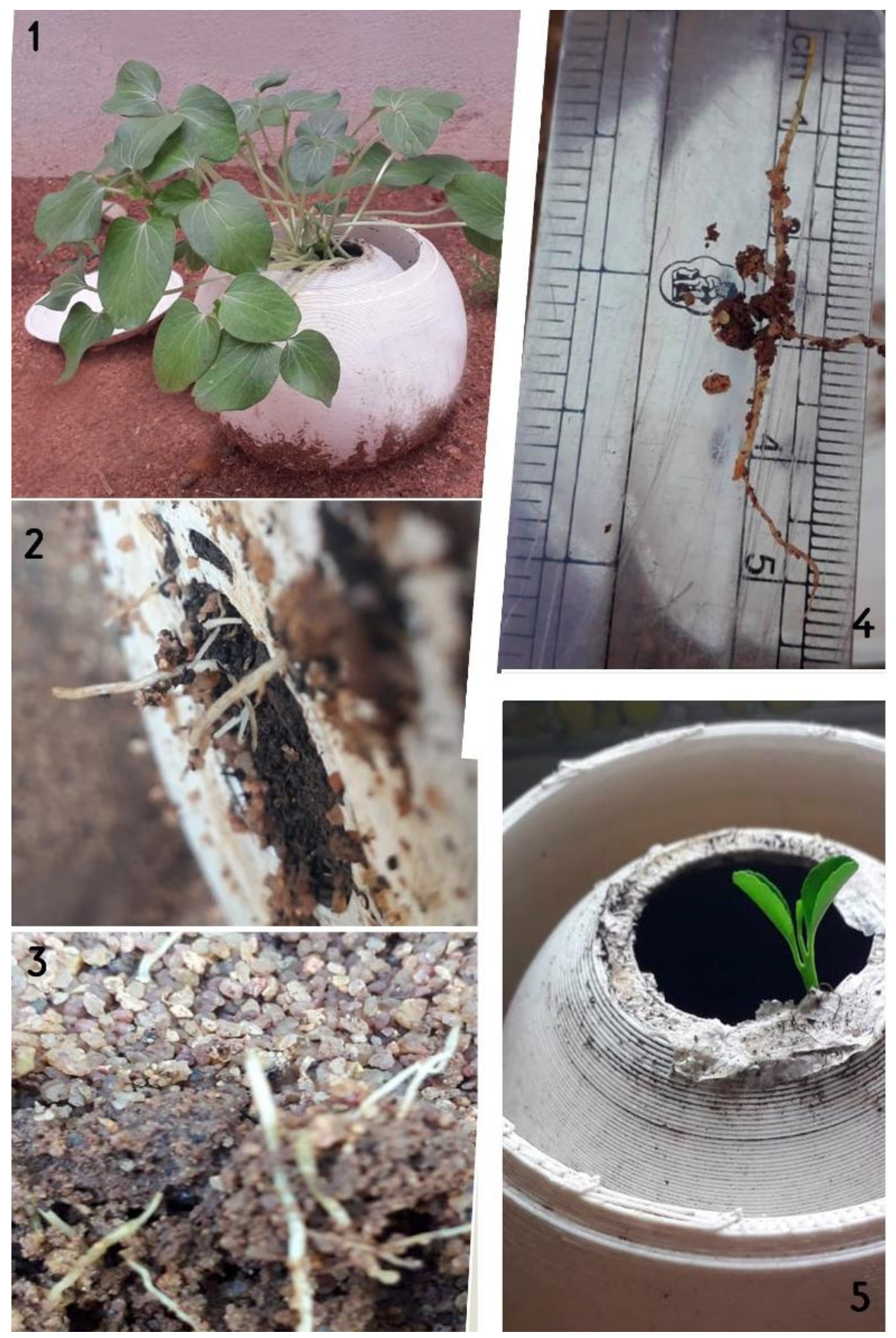

Figure.1 Robust growth of ladies finger seeds in seed wombs, Fig.2-Serrated roots emerging out of seed womb and piercing the soil Fig.3\&4-The cluster of roots in the soil and length of the roots in the soil Fig5-Growth of hardy tamarind seeds in seed wombs. Duration -20 days

Where rates of tropical deforestation are high and where formerly forested landscapes are converted into mosaics of small patches of forest remnants, forest restoration has become an increasingly important tool for species preservation and for maintaining the diversity of tropical forests communities ${ }^{1}$ Global warming is currently at the century peak with high temperature rise, draught, expanding desserts, scanty rains, drying up of lakes, ponds, rivers and underground water levels. Various species of insects, birds and animals 
are now either extinct or endangered. Greenhouse gases such as carbon dioxide, methane and nitrous oxide are at alarming high rates causing threat to life on earth. Diseases such as asthma, cancer, birth defects and various other diseases have become epidemic. Farmers are severely affected by drought as it is more difficult to grow crops with low soil moisture and no water availability and reduction in soil nutrient levels. Many cities are facing drinking water shortage. Many countries are facing drowning because of melting of glaciers.

The solution for all these problems is immediate reforestation of the planet.

Sapling plantation is the only major method to grow plants globally with which global warming and climate change cannot be solved.

Saplings are grown and obtained at a relatively advanced stage from nurseries. These nursery grown saplings are thus likely to grow faster initially than seedlings from seed. Thus, planted saplings should more effectively compete with unwanted grasses, herbs, and shrubs for moisture, nutrients and light. Successful survival is considered to be more likely when planting saplings compared to natural regeneration and direct seeding ${ }^{3}$.

Can global warming be solved and forests regenerated using sapling Plantation No. The reasons being;

Saplings are not available all round the year. So, not easily accessible to people all round the year.

Saplings are heavy to carry. People cannot carry saplings while travelling in large numbers.

Saplings require digging pits. People will not have tools required to dig pits always.

Saplings are available of only limited varieties. Forests have diverse nature. So, forests cannot be regenerated using saplings. 5.Saplings cannot be carried and planted on top of mountains, deep trenches etc in large quantities, as they are heavy and need digging pits. So saplings cannot be used in inaccessible areas like mountain peaks, deep trenches etc.

Saplings need daily watering during initial 1 to 2 years. Without water they dry up ${ }^{6}$.

Cost of saplings is high as saplings have the cost of growing them in nurseries for 6 months to 1 year, digging pits and daily watering.

Because of these practical problems there is less people's participation to grow trees. So, saplings are not effective tools to grow millions of trees immediately.

Seed Wombs are first of its kind ready to use scientific patented product to grow all varieties of plants and trees. It is a patent pending product developed by Dr.Nagaveni Aspalli.

Though there are lakhs of products available in the market, there is no single ready to use product to grow plants and trees. Dr.Nagaveni after extensive research, developed seed wombs. Seed wombs are like mother's womb. They protect the seeds from heat, wind and pests. Keeps the seeds alive and help them germinate when water is available. They provide all the nutrients required for seeds to germinate and help them and protect them until they are big enough to self sustain. Seed wombs of all varieties of plants and trees can be made. They do not require digging pits. Are very light weight. Do not require watering daily. Are easy to carry while travelling, trecking etc. They can be spread using aircrafts too to create forests in inaccessible and large areas. They have a 
shelf life of one year. Are very economical. Seed womb can be made available in all retail outlets. Make them available all round the year. So, people can easily obtain seed wombs from retail shops all round the year.

Seed womb must be placed where it is wished to be grown. That makes it practically easiest and most effective method to grow trees. The design of seed womb is such that it does not require watering daily. Since it is easy, fun, active people participation can be achieved. Government can spread Seed wombs in large open areas, on mountains, around water bodies etc to regenerate forests using aircrafts. Seed wombs are 100 percent effective. Forests can be regenerated, water bodies rejuvenated, pollution reduced, temperature reduced, creates cleaner greener healthier ecosystem and biodiversity.

\section{Advantages of Seed Wombs}

All varieties of plant species can be grown. Seed wombs are light weight and are easy to carry in bulk by people. Can also be spread in large areas, on mountains using aircrafts. Robust growth of seeds and plant is observed in seed wombs. Seed wombs do not get damaged by wind rain or heat and even on throwing impact. Requires very less water. Do not let the plant dry. Provides continuous supply of water required for the plant to grow..Forests can be regenerated easily and immediately at one fourth the cost required using saplings. People participation will increase to grow trees using seed wombs as it is simple and easy as they require no digging pits, lightweight, available round the year in retail shops.Arial spread of seed wombs can be done to create forests, rejuvenate water bodies.

\section{Fututre Benefits of Spreading Seed Wombs}

Fixes and reverses climate change and global warming.

Creates balanced sustainable ecosystem in India and the world.

Dense forests can be regenerated easily economically and rapidly.

Induces rains, recharges underground water levels and soil moisture level increases. Reduces temperature and pollution.

Improves the health of human beings, animals, birds and insects.

Seed wombs are potential solution to global warming and climate change. With seed wombs millions of hectares of forests can be regenerated. No digging pits and no daily watering makes them ideal methods for restoring forests because of scanty rainfall. Seed wombs are more effective methods compared to saplings. Seed wombs also reduce the cost of afforestation to one fouth the cost using saplings. Seed wombs are ready to use products to grow all varieties of plants.

\section{References}

1 Alcorn, J.B., 1993, Indigenous people and conservation. Conservation Biology, 7:424- 426.

2.Camilla Toulmin, Drought and the farming sector: Loss of farm animals and postdrought rehabilitation page no;1-23

3.Duryea, M.,1992, Forest regeneration methods: Natural Regeneration, Direct Seeding and Planting. Florida Cooperative Extension Service, Institute of Food and Agricultural Sciences, University of Florida, Circular 759:113.

4.Fukuoka, M.,1992, One Straw Revolution (Translated in English).Other India Press, Goa. Volume 136, April 2016, Pages 130-143

5.Iqbal M R Khan Rising temperature in the changing environment: A serious threat to plants. Climate Change and Environmental Sustainability (April 
2013) 1(1): 25-36

6.Jessica M. Vogt Explaining planted-tree survival and growth in urban neighbourhoods: A social-ecological approach to studying recently-planted trees in Indianapolis Landscape and Urban planning

7.Lucas,S.,2011,Seed Ball Experiment- Final
Report. Puente Hills Landfill Native Habitat Preservation Authority. 1-9.

8.Matt McGrath 2019. Climate change: Current warming 'unparalleled' in 2,000 years. Science and Environment

9.Young, T.P., 2000, Restoration ecology and conservation biology. Biological Conservation, 92:73-83.

\section{How to cite this article:}

Nagaveni Aspalli, Uday Kumar Nidoni, K.J.Hemalatha and Shivanand Aspalli. 2020 Comparison of Efficacy of Different Afforestation Techniques with Seed Wombs. Int.J.Curr.Microbiol.App.Sci. 9(02): 3065-3072. doi: https://doi.org/10.20546/ijcmas.2020.902.353 